\title{
A COMUNICAÇÃO VISUAL INSTITUCIONAL DO IADÊ NO PERÍODO DE 1959 A 1987
}

\author{
Auresnede Pires Stephan \\ Universidade de São Paulo \\ apsdesign@uol.com.br \\ Marcos da Costa Braga \\ Universidade de São Paulo \\ bragamcb@usp.br
}

Resumo: O ladê - Instituto de Arte de Decoração iniciou suas atividades didáticas no ano de 1959. A instituição foi concebida pelo professor, cenógrafo e publicitário Ítalo Bianchi, um imigrante italiano que chegou ao Brasil em 1949. A inquietude desse profissional em relação aos conceitos tradicionais da "decoração" na cidade de São Paulo acabou motivando-o a implantar uma nova metodologia de projeto de interiores nessa área, fundamentando seu instituto nos princípios da filosofia da escola alemã Bauhaus. Este artigo pretende fazer uma leitura sobre as peças gráficas institucionais que estabeleciam a comunicação junto aos interessados em conhecer e posteriormente se matricular nessa instituição. Para tanto, definimos como estratégia a leitura sintática e semântica da identidade visual, da programação visual da papelaria - compreendida pelo envelope e pelo papel de carta -, dos folders institucionais produzidos e distribuídos anualmente, e um folder criado pelos arquitetos Haron Cohen e Laonte Klawa concebido por ocasião da implantação do curso técnico de desenho de comunicação, no ano de 1969. As entrevistas foram baseadas nos métodos da História Oral, vistos em Alberti (2013). A análise do material gráfico foi embasada nos conceitos da ADG - Associação dos Designers Gráficos e nos textos do designer André Stolarksi, que refletem sobre a contribuição do movimento construtivista no Brasil.

Palavras-chave: Identidade visual, impressos institucionais, Construtivismo

\begin{abstract}
IADE, Institute of Art \& Decoration, started its educational activities in 1959. It was the brainchild of Italo Bianchi, a professor, set designer and marketing man, an immigrant who came from Italy to Brazil in 1949. Bianchi's dissatisfaction with traditional "decoration" concepts in São Paulo motivated him to introduce a new methodology of interior design, creating his Institute based on the philosophical principles of the German Bauhaus school. This article intends to review the institutional graphic design pieces created at IADE in order to communicate the Institute's signature work to those interested in getting to know it and possibly to enroll in it. With this aim in mind, we defined a strategy of
\end{abstract}


syntactic and semantic readings of the visual identity pieces, stationery design (envelopes and letter sheets) and institutional folders produced and distributed annually by IADE, as well as a folder created by architects Haron Cohen and Laonte Klawa especially designed for the launching of the new Communication Design technical course, in 1969. The interviews were based on methods of Oral History, as seen in Alberti (2013). The analysis of the graphic material was based on concepts by ADG, Associação dos Designers Gráficos (Brazilian Association of Graphic Designers) and on texts written by designer André Stolarksi that reflect on the contribution of the Constructivist movement in Brazil.

Keywords: Visual identity, institutional graphic design, Constructivism

\section{INTRODUÇÃO}

O ladê foi idealizado como um centro formador de pessoas capazes de criarem novos conceitos, primeiramente direcionado à arquitetura de interiores, com forte influência da tradicional escola alemã Bauhaus. Em sua fase inicial teve a oportunidade de formar um grande contingente de profissionais e de implantar um escritório profissional, na própria instituição, que atendia o mercado, um diferencial que se compara, nas últimas décadas, às chamadas "empresas juniores". No entanto, a formação no curso de decoração não possibilitava aos formandos uma titulação de nível superior. Em 1968, com a contribuição de jovens e talentosos arquitetos recém-formados capitaneados pelo professor Emílio Fernandez Cano, a escola passa a ser estruturada para se enquadrar no sistema oficial de ensino técnico. Com isso acreditava-se na formação de um técnico nas áreas de Artes, Comunicação Visual e Desenho Industrial respaldado pela legislação da Secretaria da Educação, e que estaria preparado para prestar vestibular nos cursos de Arquitetura e Urbanismo, Desenho Industrial e Comunicações, que estavam sendo implantados naquela época.

Inseridos na trajetória do ladê estão a sua identidade institucional e seus impressos, que fazem parte de sua memória histórica e gráfica. Essa memória, como se procurará abordar neste artigo, está naturalmente associada a possíveis influências de movimentos como o Construtivismo, particularmente de seu desdobramento mais importante, a arte concreta, somada à liberdade advinda das novas formas de expressão das artes visuais e da fotografia, entre outras.

\section{A IDENTIDADE VISUAL DO IADÊ}

A criação da identidade visual do Instituto foi de responsabilidade de Ítalo Bianchi, tendo como colaborador o professor Álvaro Landerset Simões, e criada no final de 1958, pouco antes do início das atividades letivas. A partir de documentos do acervo particular de Maria Isabel de Souza Franco, constatamos que essa identidade não sofreu, ao longo de toda a sua existência de vinte e oito anos, nenhuma reformulação ou rejuvenescimento na estrutura gráfica, como também nas cores institucionais (preto e laranja). Em entrevista concedida por Maria Isabel de Souza Franco, fica evidente que Ítalo Bianchi, ao desenvolver a identidade do Instituto, conceituava seu projeto dentro das leis enunciadas pelo arquiteto Max Bill, que estudou na Bauhaus e 
era expoente da arte concreta, que pressupunham: "o alinhamento, o ritmo, a regularidade e a lógica interna de desenvolvimento e construção". Esses conceitos projetuais foram princípios que Ítalo Bianchi disseminava em suas aulas de História da Arte, tendo como referência a pedagogia da Bauhaus.

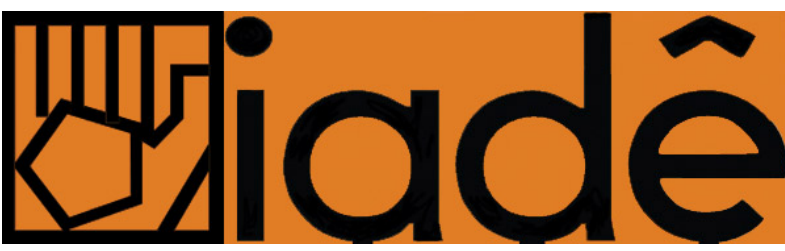

Fig.1 A identidade pela simbologia e lettering

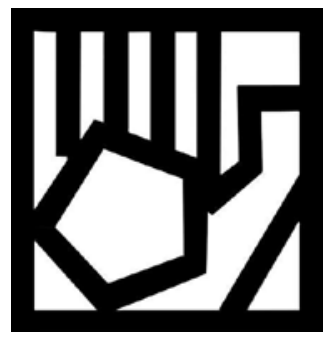

Fig.2 Mão espalmada

(Acervo pessoal de Auresnede Pires Stephan)

A identidade (Fig.1) é constituída pela simbologia da mão acompanhada do lettering ladê ao seu lado direito. O conceito estabelecido simbolicamente foi o da geometrização da "mão espalmada do desenhista", (Fig.2) com características sintéticas de um pictograma, trazendo a mão inserida dentro de um retângulo definido por linhas espessas. A palma da mão estilizada é configurada por um pentágono regular. Aqui podemos fundamentar a semântica do conceito simbólico da mão a partir de Ronnenberg (2012: p.380):“Como primeiros instrumentos de criatividade, as mãos do Homo Faber imitam a mítica transformação da matéria num ser distinto por divindades que gravam, esculpem, tecem e forjam a criação. As mãos significam o alcance soberano da criação do mundo consciente; elas personificam a eficácia, diligência, adaptação, invenção, autoexpressão e a posse de uma vontade para fins construtivos e destrutivos."

O nome utiliza letras desenhadas, provavelmente tendo a família tipográfica Futura ou outras fontes geométricas como inspiração, em caixa baixa ${ }^{1}$. Aqui, na utilização deste tipo de fonte, podemos observar um dos princípios conceituais de Herbert Bayer, gráfico, tipógrafo e professor da Bauhaus, que desenvolveu o princípio de um alfabeto de legibilidade universal. No seu entender, "tal como máquina, arquitetura e cinema moderno, o alfabeto deve também ser uma expressão dos nossos tempos". Bayer, ao criar o alfabeto experimental Sturm Blond, pensou poder superar os limites definidos pelo vai e vem das modas. Para tanto, subordinou o seu desenho de letras a leis supostamente "atemporais" e "objetivas". A fonte tipográfica, que se caracterizava pela clareza, com evidente construção geométrica, aliava os conceitos de sobriedade, neutralidade, equilíbrio e alta legibilidade. Considerações sintáticas e semânticas semelhantes justificaram o uso de letras sem serifas geométricas por Ítalo Bianchi para a concepção do logotipo do Instituto.

\footnotetext{
${ }^{1}$ Apesar da semelhança, observamos diferenças entre elas e as letras da fonte Futura, como a proporção do pingo do 'i' e o final da curva do 'e'.
} 


\section{FOLHETOS INSTITUCIONAIS DO IADÊ}
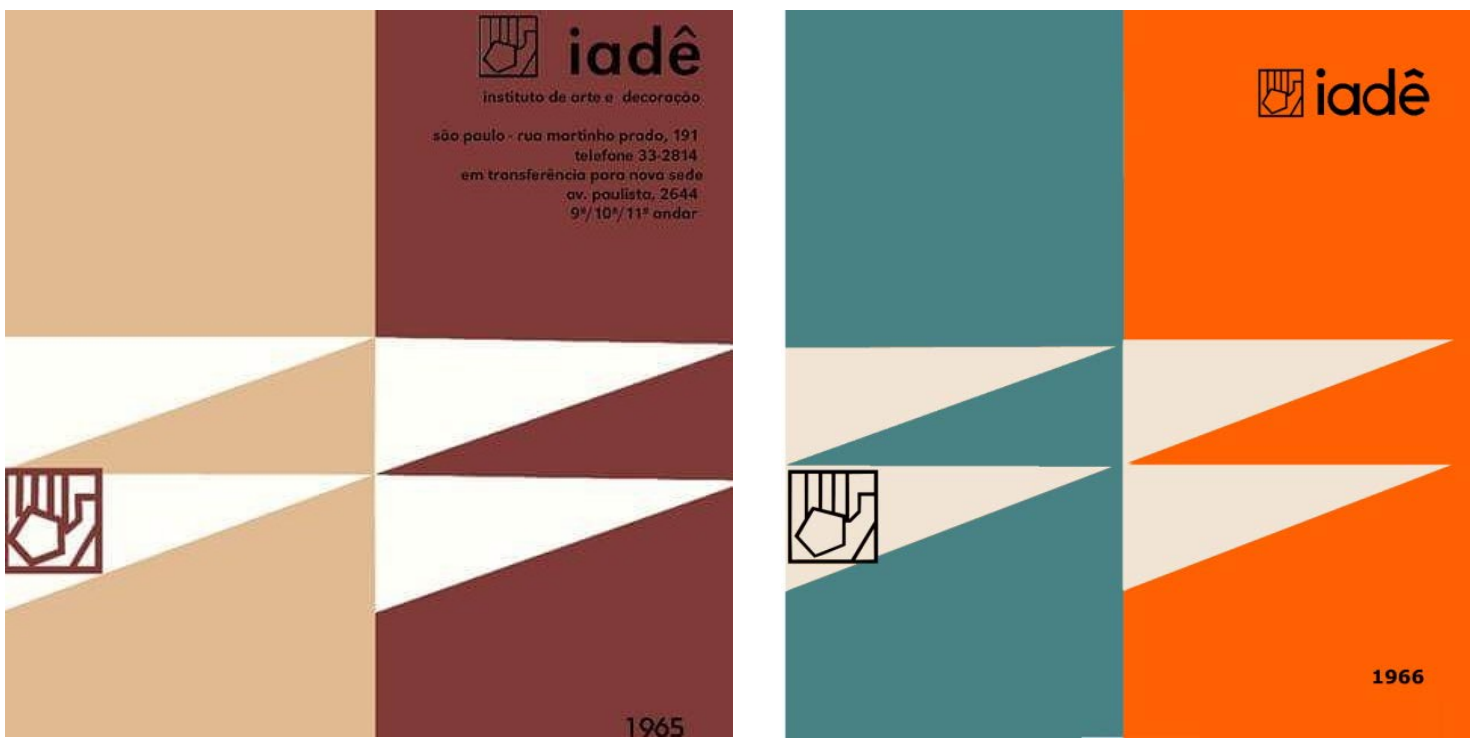

Figs. 3 e 4 Folhetos no formato vertical (Acervo pessoal de Auresnede Pires Stephan

Adotando um formato vertical, com dimensões de $9 \times 20 \mathrm{~cm}$ (fechado), e com a média de 12 a 16 páginas (Figs.3 e 4), o ladê produziu, no decorrer de vários anos, seus folhetos institucionais, que podemos considerar como guias de orientação sobre os cursos e a filosofia da instituição. Essa produção gráfica foi também concebida por Ítalo Bianchi, e posteriormente prosseguiu sendo diagramada por colaboradores do estúdio profissional do Instituto. Esses folhetos não sofreram grandes mudanças na sua concepção estrutural com o passar do tempo, mas sim no conteúdo editorial e nas cores das primeiras e últimas capas, que se distinguiam por uma paleta sóbria, preponderando as cores laranja, azul e verde acompanhadas de tons cinza e do branco.

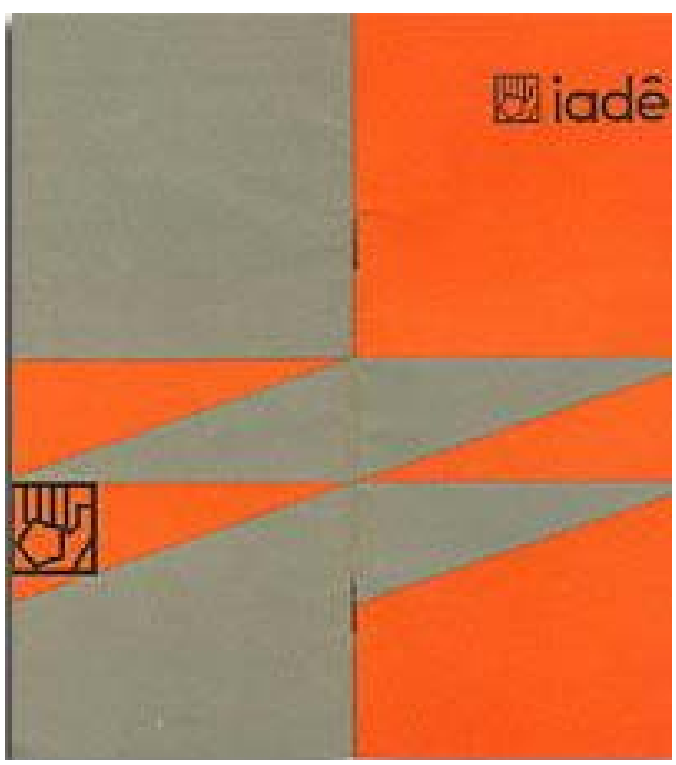

Fig. 5 Localização da identidade visual

(Acervo pessoal de Auresnede Pires Stephan) 
A identidade visual completa (símbolo e tipografia), sempre em destaque, era localizada na parte superior da capa na cor preta (Fig.5) e na última capa era inserido apenas e tão somente o símbolo sem o nome. Na primeira página, na parte superior, ficavam a identidade visual e o endereço completo da instituição, e logo em seguida um texto introdutório. O miolo compreendia uma diagramação com texto justificado, utilizando-se única e exclusivamente de uma família gráfica em caixa baixa. Somados aos textos, encontramos também informações sobre o perfil dos cursos, períodos e duração dos mesmos, cargas horárias e organogramas da estrutura administrativa e didática da instituição (Fig.6).

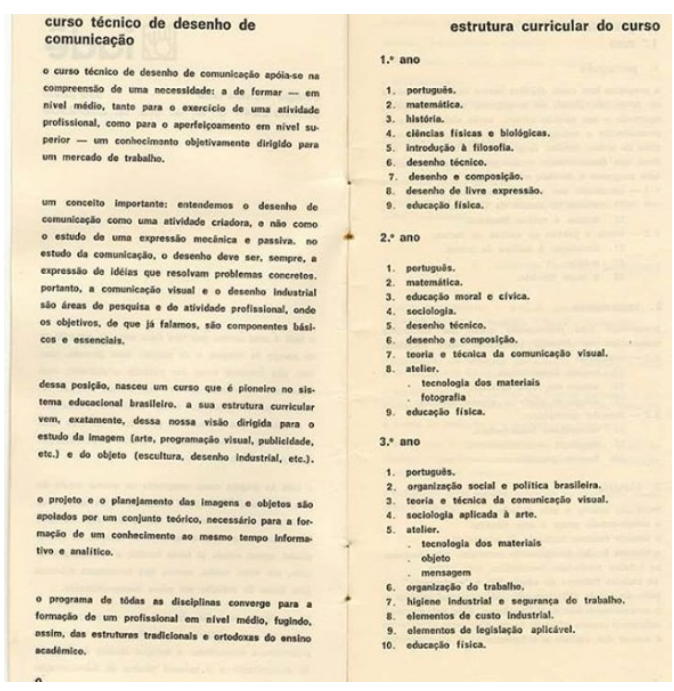

Fig.6 Diagramação do miolo do folheto

Na concepção das capas (Fig.7), podemos observar uma possível influência do conceito da Arte Concreta, por suas estruturas geométricas configuradas por meio de triângulos apresentados com dinamismo visual devido a suas dimensões e seu posicionamento no campo gráfico, somadas ao efeito ótico na inversão das cores entre a capa e a última capa.

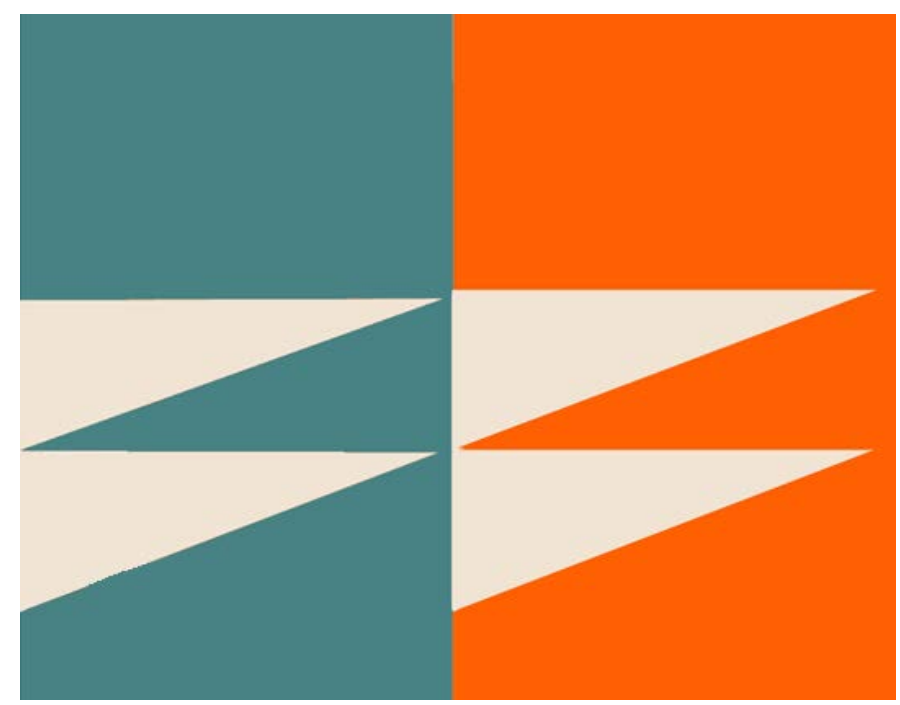

Fig. 7 Concepção das capas 
No entanto, precisamos atentar para as observações de André Storlarski, reticente quanto às manifestações e reflexões do movimento construtivista:

se é verdade que um "otimismo projetual" animava todos os envolvidos, não havia, por outro lado, homogeneidade no tipo de envolvimento ideológico com a "causa" concreta, seja na utilização estrutural ou estilística de seus referenciais, seja no modo de entender a relação entre a figura do artista plástico e o designer...

Aqui podemos estabelecer possíveis questionamentos sobre a "influência" do movimento concretista no material gráfico do ladê: certos princípios gráficos remetem ao conceito funcional do movimento, mas não fica evidente se essa filosofia foi efetivamente adotada ou se as propostas visuais são apenas alusões meramente sintáticas.

\section{IMPRESSOS BÁSICOS}

Os impressos básicos eram constituídos por envelope no formato de $12,0 \times 23,4 \mathrm{~cm}$ e do papel de carta de $20,3 \times 27,0 \mathrm{~cm}$. As limitações financeiras da instituição, em toda a sua existência, somadas às necessidades daquele período, resultavam em um número restrito de peças de comunicação (Figs.8 e 9).
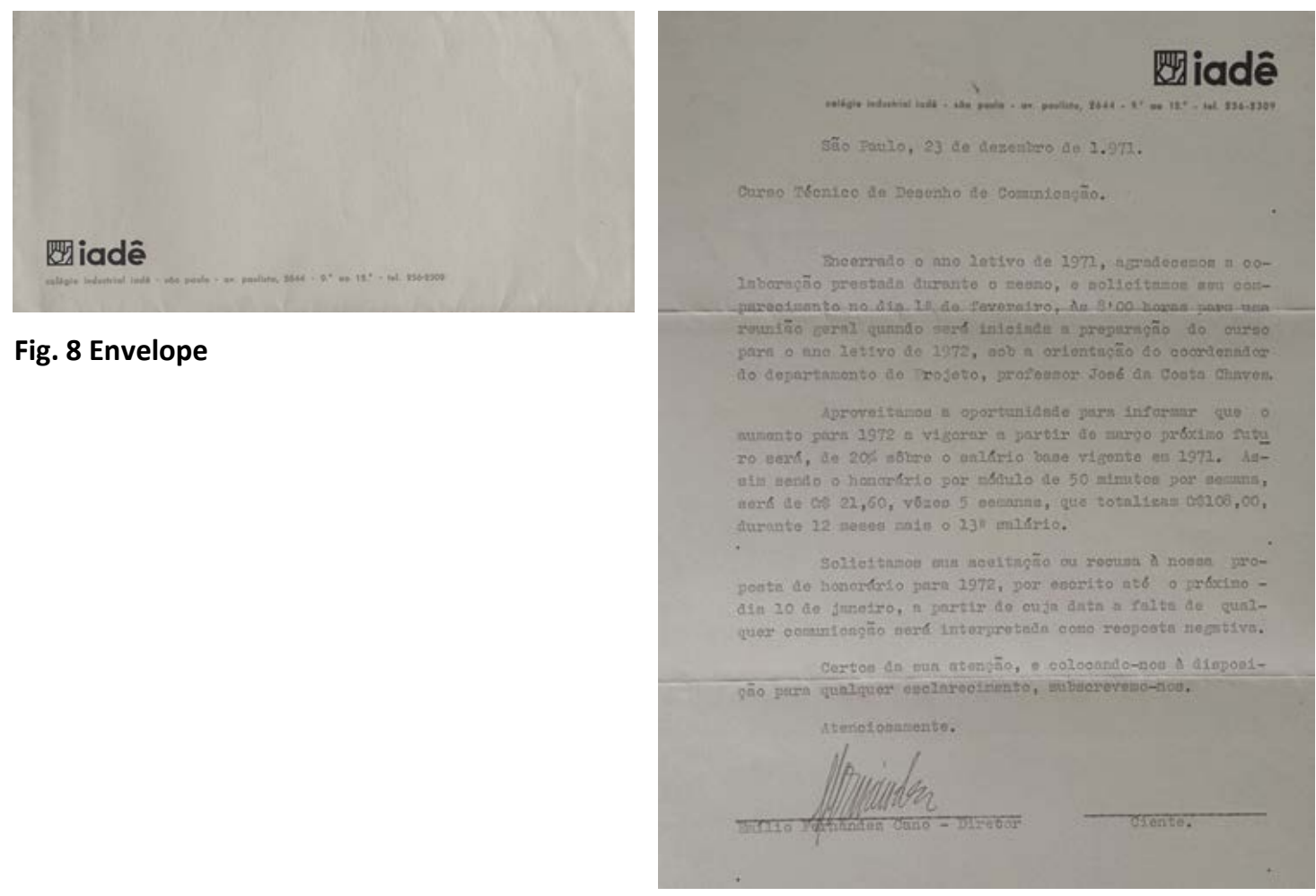

Fig.9 Papel de Carta

$\mathrm{Na}$ organização gráfica do papel de carta e do envelope encontram-se a identidade constituída pelo símbolo e pela tipografia, acompanhada da assinatura "colégio industrial iadê - são paulo - av. paulista, 2644 - 9o ao 12ㅇ - tel. 256 2309”. Já a paleta 
de cores obedecia a seguinte ordem: a identidade visual sempre em preto e a assinatura sempre na cor laranja. Cumpre aqui destacar que nas pesquisas realizadas não existe nenhuma referência ao por quê da escolha das cores laranja e preto como código cromático do Instituto. No envelope, a identidade visual e a assinatura estão localizadas na parte frontal e inferior do envelope, sendo que a identidade encontra-se do lado esquerdo numa distância de $1.4 \mathrm{~cm}$ da borda esquerda do envelope. No papel de carta, no entanto, o conjunto da identidade e assinatura está localizado na parte superior, com alinhamento do lado direito e margem de $1,6 \mathrm{~cm}$ da borda direita do papel. O processo de impressão é tipográfico, utilizando-se de clichês.

\section{HARON COHEN E A CRIAÇÃO DO FOLDER DE 1969}

Após o desligamento de Ítalo Bianchi da instituição no ano de 1967, o professor Emílio Fernandez Cano e os ex-alunos Maria Isabel de Souza Franco e Michiro Motoda assumiram a direção e administração do ladê, mantendo, no entanto, a filosofia dos cursos existentes somada à implantação dos cursos colegiais técnicos de nível médio: Técnico de Desenho de Comunicação (1969 a 1987) e Técnico em Administração de Empresas (1969 a 1976).

No depoimento concedido pelo arquiteto Haron Cohen (Fig.10), formado pela Universidade Mackenzie no ano de 1963, ele nos conta que, simultaneamente à estruturação de seu escritório, teve a oportunidade de ministrar aulas no colégio técnico do ladê. Posteriormente, lecionou na FAAP, sendo um dos professores fundadores do curso de Desenho Industrial, e na FAU/USP - Faculdade de Arquitetura e Urbanismo de São Paulo, onde também realizou o seu mestrado.

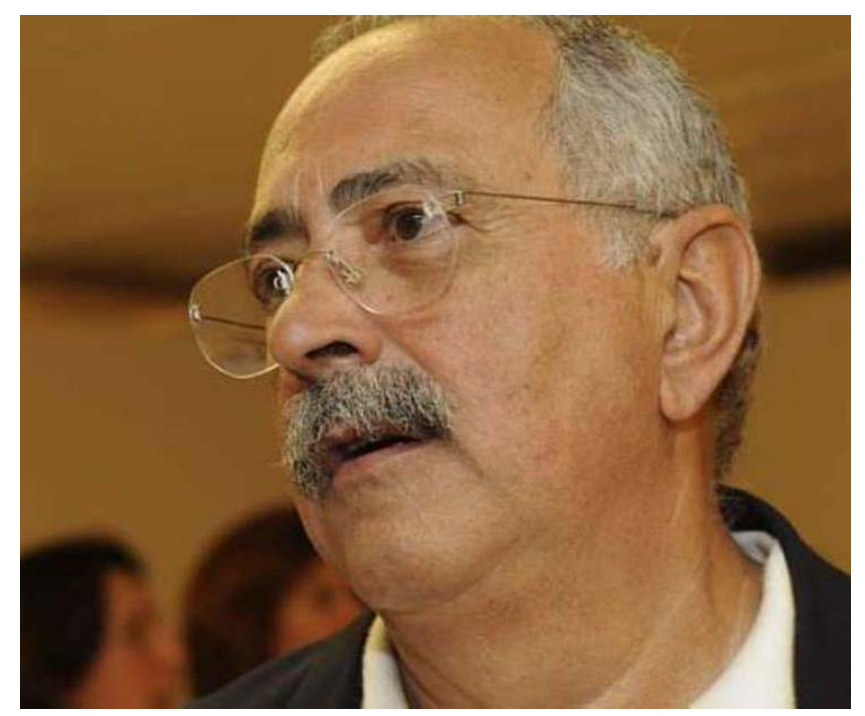

Fig. 10 Haron Cohen (Acervo pessoal de Haron Cohen)

Haron Cohen conviveu com a efervescência do modernismo e a implantação da industrialização no país. Nos anos 1960, fez parte de uma geração atuante no âmbito cultural e político. Em seu período acadêmico, atuou também no IAB - Instituto dos Arquitetos do Brasil (que naquele período aceitava a categoria de sócios-estudantes). Nesse contexto nasceu seu interesse pelo desenvolvimento de cartazes e projetos editoriais para a universidade e para o instituto. Ele sofreu uma forte influência de Peter Max Finkelstein, artista gráfico americano nascido na Alemanha e conhecido pela 
utilização de formas psicodélicas e paletas de cores contrastantes, somadas ao uso de múltiplas expressões gráficas, tais como desenho, colagem, pintura, fotografia, ilustração, incluindo também o universo da mass-media. Essas referências influenciaram os projetos do arquiteto e Ihe possibilitaram uma ampla gama de resultados gráficos que, no seu entender, embasaram também seus projetos arquitetônicos. Ao ingressar no ladê, teve a oportunidade de ministrar a disciplina de Composição (Projeto) e editar uma das publicações pioneiras de Histórias em Quadrinhos no âmbito acadêmico.

Nesse ambiente, em conjunto com o arquiteto Laonte Klawa (que já pertencia ao quadro de professores do ladê) e incentivado pela liberdade de criação oferecida pelo professor Emílio Fernandez Cano, foi o responsável pela criação da peça gráfica institucional de divulgação dos cursos tradicionais e também do colégio técnico. Esse folder foi o último material impresso de promoção institucional, pois, devido às dificuldades econômicas, posteriormente o Instituto deixou de produzi-los. 0 projeto gráfico de Haron Cohen é praticamente uma síntese da sua trajetória naquele período histórico, acrescido de novas estruturas sintáticas construtivas do "desenho industrial" daquela época. Para entender essa influência neste trabalho de Cohen no contexto daquele período, podemos nos reportar aos conceitos de André Storlaski a partir da seguinte afirmação:

...no Brasil, não é nenhum exagero dizer que as transformações produzidas pelas tendências construtivas nas artes plásticas, na literatura e no design foram igualmente importantes. A palavra influência, por exemplo, é tímida para ilustrar o impacto da arte construtivista no design brasileiro.

O arquiteto Haron Cohen, em suas considerações técnicas sobre a peça gráfica, deixa evidente o uso do conceito da fotografia analógica na primeira (Fig.11) e na última capa.

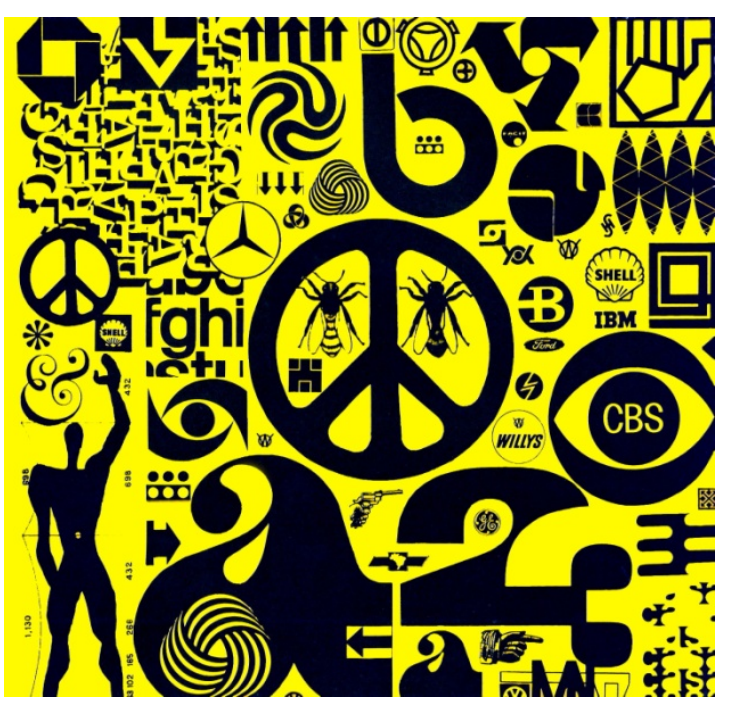

Fig. 11 Capa

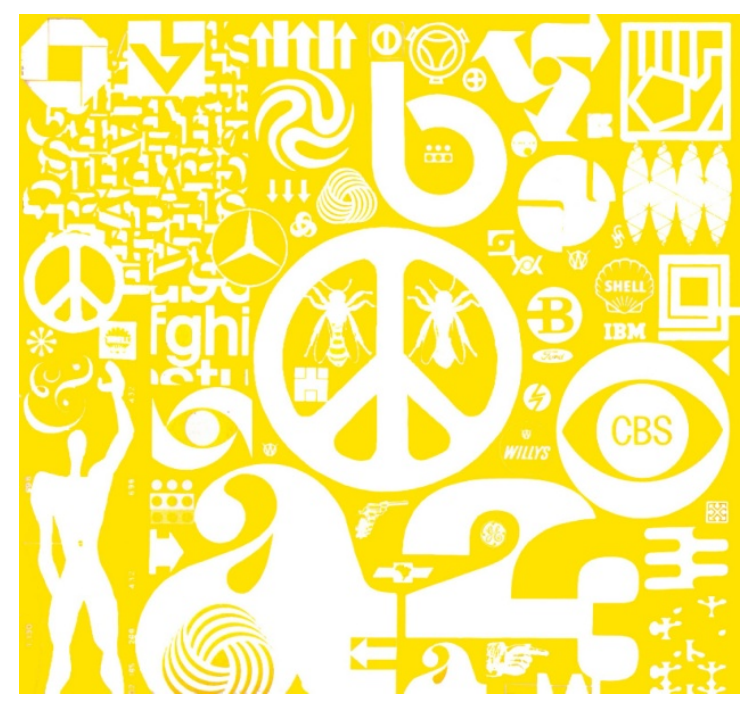

Fig. 12 Última capa

(Acervo pessoal de Auresnede Pires Stephan) 
Na primeira, opta por uma imagem positiva, texto em preto sobre o fundo amarelo; na última (Fig.12), a imagem negativa, ou seja, branco sobre fundo amarelo. As imagens escolhidas para a capa formam um conjunto de marcas gráficas, em diversas dimensões, de empresas multinacionais e nacionais. Cumpre destacar que ela homenageia, por meio dessas imagens, alguns profissionais brasileiros, como Ruben Martins, Alexandre Wollner, Maurício Nogueira Lima, Aloísio Magalhães, entre outros. As proporções humanas estão representadas pelo modulor de Le Corbusier. No centro da capa está o símbolo criado pelo artista e designer Gerald Holtom (1914-1985), que, atuando em movimentos contra a guerra, concebeu um símbolo relativamente simples composto por um círculo - significando a unidade - no qual estão inscritas duas letras sinaléticas, o N (para nuclear) e o D (para desarmamento); essa organização sintática nos revela, no entender do criador, o "ser humano desesperado" na iminência de uma guerra nuclear. Esse símbolo transcendeu seu uso original e hoje é reconhecido em todo o planeta como sinal de paz. Ao utilizá-lo no folder, Haron Cohen inseriu nele insetos, algo inusitado num projeto dessa natureza, mas que é de certa forma um "ruído visual" criado para expressar o mundo animal.

No miolo do folder (Figs.13 a 22) há uma pequena transgressão: a paginação foi invertida, como uma contagem regressiva inspirada na abertura de filmes da época. Encontra-se primeiramente a página nove, e na sequência chega-se à zero. Essa numeração interage com o texto tanto pelo tamanho avantajado como pela definição da paleta de cores.

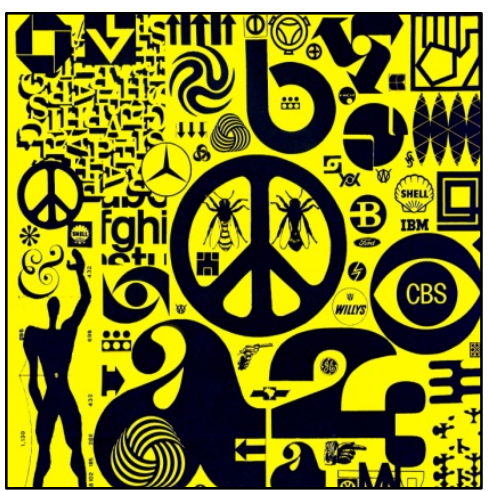

Capa

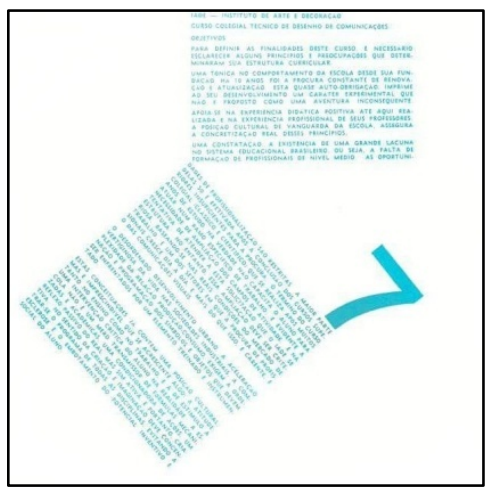

Fig.15

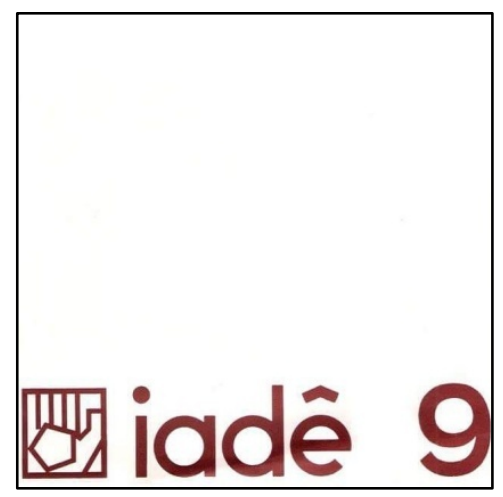

Fig.13 Miolo do folder

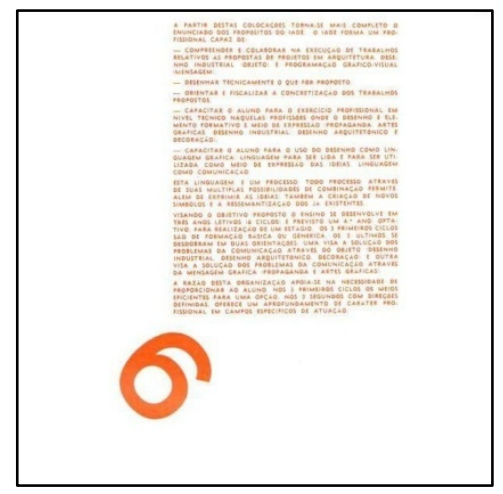

Fig.16

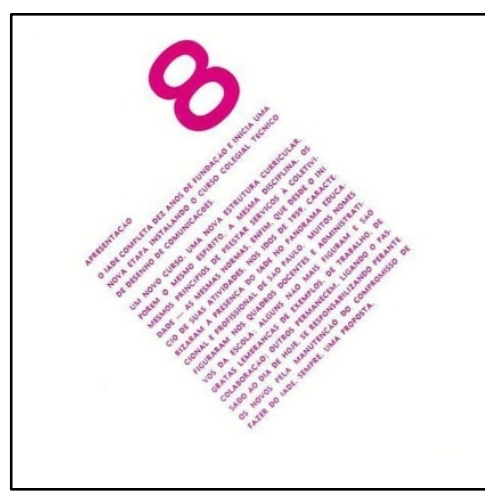

Fig. 14

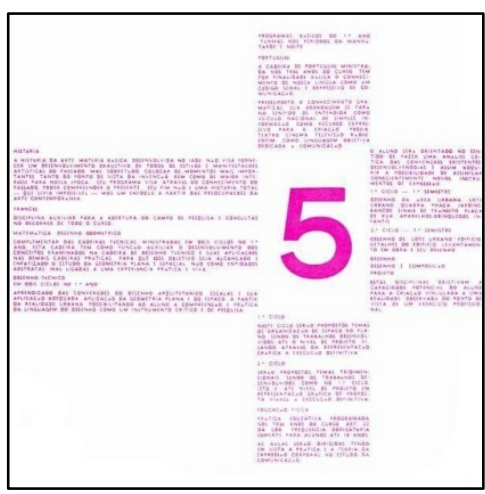

Fig.17 


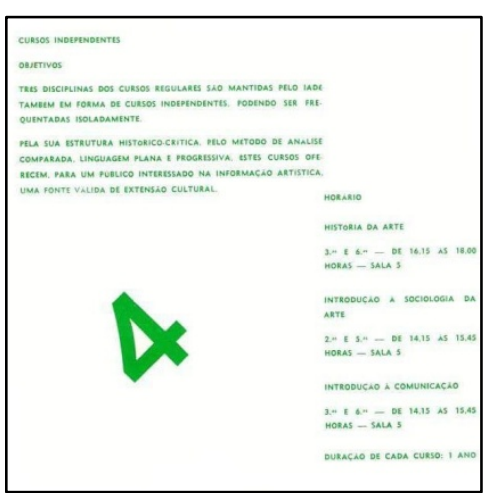

Fig. 18

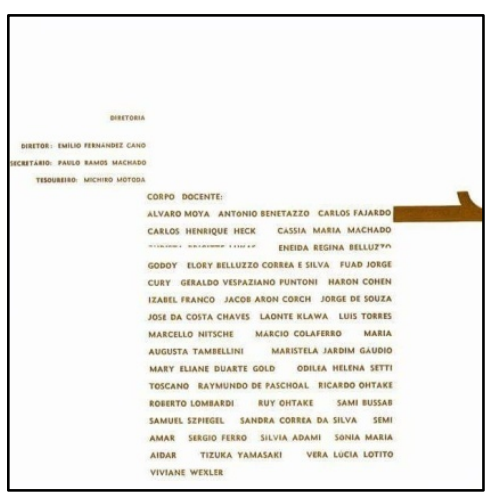

Fig. 21

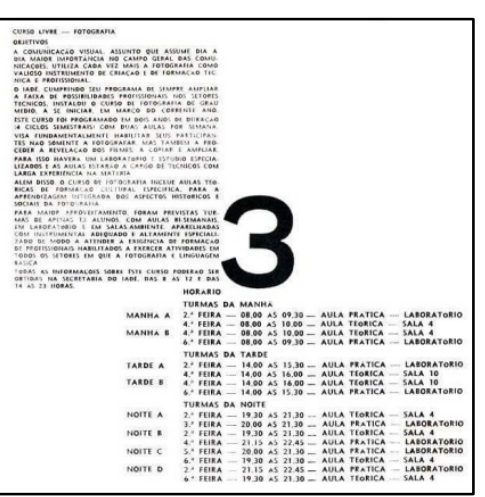

Fig. 19

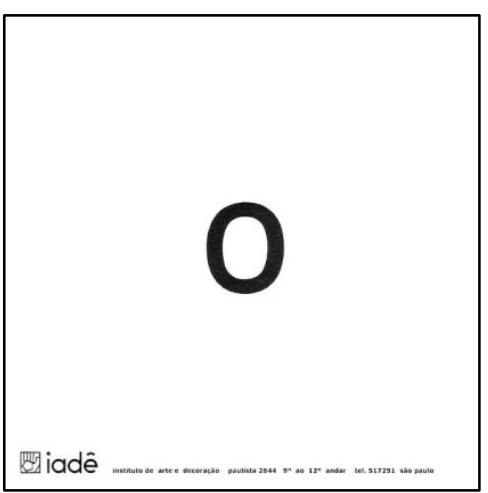

Fig. 22

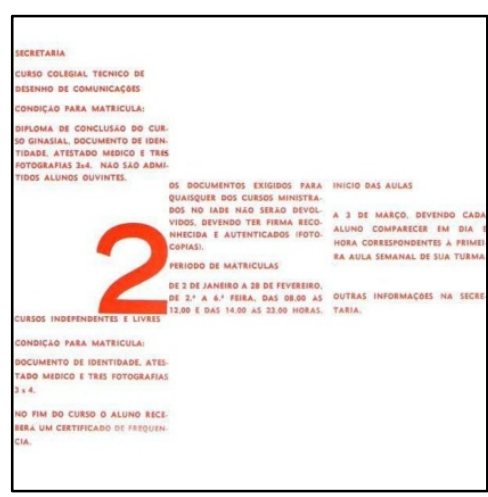

Fig. 20

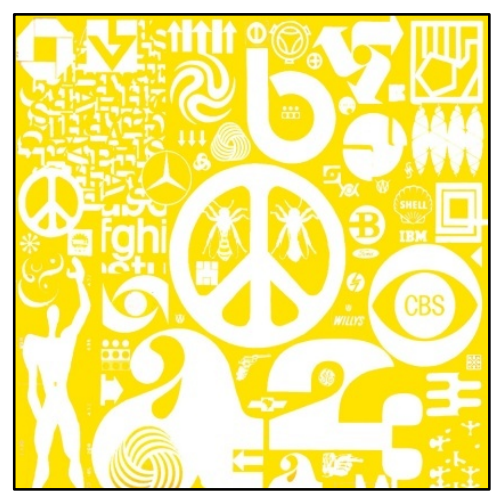

Última capa

(A sequência de imagens pertencem ao acervo pessoal de Auresnede Pires Stephan)

Em suas observações, o arquiteto Haron Cohen ressalta que foi a única vez em que desenvolveu uma numeração de páginas usando o elemento cor. Outros elementos merecem ser destacados nesse projeto gráfico: a utilização da caixa alta nos textos em todas as páginas, que no entender do autor é um fator que possibilita definir com mais precisão as formas geométricas blocadas com quadrados e retângulos, e a articulação gráfica dos blocos de textos, sejam na horizontal, na diagonal, em um único bloco ou em dois ou mais blocos, estabelecidos a partir dos conceitos utilizados pela poesia concreta. Para ele, a expressão gráfica da poesia concreta foi uma das referências primordiais para a definição da diagramação do miolo dessa peça gráfica².

No entanto cabe aqui, mais uma vez, refletir sobre o texto de André Storlaski, que questiona a amplitude e as vertentes da poesia concreta:

...há que tomar cuidado com a avaliação coletiva. Assim como não existe uma poesia concreta, mas poesias concretas, não faz sentido eleger uma vertente privilegiada ou hegemônica do design na relação com a arte concreta, e certamente não há como falar em um "design concreto" a não ser como delimitação puramente estilística e, para nossos fins, vazia". Se é verdade que um "otimismo projetual" animava todos os envolvidos, não havia, por outro lado, homogeneidade no tipo de envolvimento ideológico com a "causa"

\footnotetext{
${ }^{2}$ Depoimento dado por Cohen ao autor em 2015.
} 
concreta, seja na utilização estrutural ou estilística de seus referenciais, seja no modo de entender a relação entre a figura do artista plástico e o designer...

O que nos leva a entender que no projeto desenvolvido por Haron Cohen houve uma aproximação com a poesia concreta e uma interpretação de seus princípios transpostos para alcançar seus possíveis futuros alunos por meio de padrões inovadores para a época e que vários artistas daquela geração também utilizaram.

No que diz respeito à execução, os arquitetos seguiram as técnicas tradicionais de elaborar um layout a lápis, past-up para colagem de textos e imagens, e a arte final em prancha rígida coberta por overlay; quanto à impressão, foi contratada junto à Furest, que naquele período era considerada pelos designers como uma "butique" das artes gráficas. Essa gráfica de pequeno porte, localizada na rua Augusta, foi inaugurada em 1966 e oferecia clicheria e impressão offset.

\section{CONSIDERAÇÕES FINAIS}

Se, por um lado, a identidade visual do ladê permaneceu inalterada durante toda a sua existência, calcada em princípios da filosofia do seu fundador, que se baseava em conceitos estéticos da Bauhaus, o folder de lançamento do curso técnico de comunicação refletiu os novos tempos. No entanto, Ítalo Bianchi, mesmo cultuando os princípios conceituais da Bauhaus, sofreu as naturais influências do contexto paulistano da Arte Concreta, capitaneada por Geraldo de Barros, Willys de Castro e Hércules Barsotti, entre outros, como inspiração para desenhos de marcas gráficas. Já a poesia concreta dos anos 1950, liderada por Décio Pignatari, serviu de referência para a dupla de designers Haron Cohen e Laonte Klawa na concepção do miolo do folder do ladê, em 1969, somando-se a isso a forte influência dos movimentos da cultura pop e das mass-media da segunda metade dos anos 1960 na construção da capa e da contracapa do referido folder. A identidade visual e todas as demais manifestações gráficas de comunicação do ladê primaram por uma preocupação constante em refletir o conteúdo educacional ministrado em sintonia com o contexto das manifestações visuais da época. No seu período inicial, caracterizado pelos princípios da Gestalt, que fortemente influenciou a arte concreta brasileira, e em seguida pelas manifestações da Pop Art e pela globalização da cultura.

\section{REFERÊNCIAS}

ADG. ABC da ADG. São Paulo: Blucher, 1998.

ALBERTI, V. Manual da História Oral. Rio de Janeiro: FGV, 2005

Catálogo Concreta 56 a raiz da forma. Museu de Arte Modena. São Paulo. SP. 2006

DROSTE, Magdalena. Bauhaus 1919-1933. Bauhaus-Archiv Museum für Gestaltung. Berlin. Taschen, 2010

COHEN, Haron. Entrevista concedida a Auresnede Pires Stephan. São Paulo, SP, Brasil. 1 h30 de duração. 18 de dezembro de 2015

FRANCO, Maria Isabel de Souza. Entrevista concedida a Auresnede Pires Stephan. São Paulo, SP, Brasil. 2h de duração. 21 de novembro de 2015 
FINK, Lenora. Projeto ladê resgate. TCC do Curso de Especialização em Design Multimídia SENAC. São Paulo, 2005

RONNENBERG, Ami. O livro dos símbolos. Reflexões sobre imagens arquetípicas.

Taschen.Germany, 2012

www.iadedesign.com.br (Acessado em 05.04.2016) 